\title{
A case of needle embolism in a drug abuser, a diagnostic and therapeutic challenge
}

\author{
Valentina Scheggi ${ }^{1 *} \mathbb{D}$, Tiziano Mariani ${ }^{2}$, Carlotta Mazzoni ${ }^{2}$ and Pier Luigi Stefàno ${ }^{3}$
}

\begin{abstract}
Background: Needle embolism is a rare complication of intravenous habit. Clinical manifestations include recurrent pericarditis, tamponade, cardiac perforation, and infective endocarditis. We describe the case of needle embolization in a young intravenous opiate abuser.

Case presentation: We describe a rare complication of intravenous misuse in a 23-year-old patient. He presented at the emergency department with chest pain and shortness of breath. He complained of remittent fever ensued 6 months before. Echocardiographic and radiologic images revealed pericardial effusion and a needle fragment inside the pericardium. The needle was removed through left-anterior mini-thoracotomy, after CT-guided carbon tracking.

Conclusions: The presence of a foreign body within the heart resulted from the migration of a needle fragment from a peripheral vessel. It caused fever and recurrent pericarditis. In similar cases, surgical extraction is the therapy of choice.
\end{abstract}

Keywords: Cardiac tamponade, Embolism, Needle, Pericardial effusion, Drug abuse

\section{Background}

Needle embolism may be a rare complication of intravenous drug abusers, which has only been reported on rare occasions. Potential sequelae include cardiac perforation, tamponade, infective endocarditis, and recurrent pericarditis $[1,2]$.

A foreign body within the heart may result either from a direct injury to the heart or from embolization to the heart from distal sites, such as the migration of a needle fragment or a catheter from a peripheral vessel [1].

The embolism of fragments into the heart is favoured by reduced vascular turbulence and by the presence of hypotension, and it depends on the patient's position

\footnotetext{
* Correspondence: scheggiv@aou-careggi.toscana.it; valentina.scheggi@gmail.com

All authors take responsibility for all aspects of the reliability of the data presented and their discussed interpretation.

'Division of Cardiovascular and Perioperative Medicine,

Cardiothoracovascular Department, Azienda Ospedaliero-Universitaria

Careggi and University of Florence, Largo Brambilla 3, 50133 Florence, Italy

Full list of author information is available at the end of the article
}

and the weight and shape of the foreign body; lower weight and smaller calibre facilitate embolization [2-4].

Foreign bodies can be trapped in the right cavities of the heart within the trabeculae of the endocardium with a fibrosis process, not causing clinical symptoms [5].

The most common symptomatic clinical manifestations are fever, pericarditis, and pericardial effusion, hemopericardium, arrhythmias, and also the formation of intracavitary thrombi. Fever is often the result of infection of the pericardium and/or endocardium by contaminated needle fragments [6].

Recurrent pericarditis and pericardial effusion, often due to an irritative stimulus given by the foreign body, are quite common in patients treated conservatively [7].

\section{Case presentation}

A 23-year-old heroin-addicted man was admitted to our department because of chest pain ensued 6 months before; the pain was sharp, was relieved by sitting up and leaning forward, and increased with coughing and

\section{Springer Open}


swallowing. He also complained of fatigue and fever for 1 month before the presentation. His previous medical history was unremarkable. Echocardiography revealed non-haemodynamic pericardial effusion and right-sided pleural effusion, treated with thoracentesis. Three blood culture samples were negative. Cardiac biomarkers were negative. Human immunodeficiency virus (HIV), hepatitis $B$ virus $(\mathrm{HBV})$, and hepatitis $\mathrm{C}$ virus ( $\mathrm{HCV}$ ) serology were negative. He was treated with colchicine and ibuprofen and empiric antibiotic therapy with an initial improvement of symptoms. Echocardiography showed a progressive reduction of the effusion. The chest X-ray confirmed the pleural effusion resolution, with no other relevant findings. The diagnosis at discharge was idiopathic pericarditis. After 4 weeks from the discharge, the patient presented a recurrence of symptoms needing new access to the emergency care department. At admission, he was normotensive and apyretic; initial laboratory exams showed a white blood cell count of $15 \mathrm{~K} / \mu \mathrm{L}$ and C-reactive protein of $105 \mathrm{mg} / \mathrm{L}$.

An electrocardiogram showed widespread concave STsegment elevation, and an echocardiogram revealed pericardial effusion relapse.

Chest radiography showed an unusual image near the right ventricle. The patient underwent computed tomography angiography that was able to localize a needle inside the pericardium (Fig. 1). A second echocardiogram confirmed the presence of the fragment in the pericardial cavity, beside the right ventricle (Fig. 2).

Before surgery, we performed a CT-guided carbon tracking of the needle.

The patient underwent left-anterior mini-thoracotomy, through the fifth intercostal space, with incision of the parietal pericardial layer and removal of $500 \mathrm{~mL}$ of haemorrhagic pericardial fluid.

The needle was easily found near the right ventricle, embedded in the thoracic wall, and was cautiously removed with a surgical needle driver (Fig. 3); it had an extremity inside the pericardial space, but without ventricular muscle laceration. After surgery, pericardial drainage was positioned; it was removed after 2 days because of the absence of fluid.

The patient's condition remained stable, and he was discharged home 1 week after surgery; echocardiography demonstrated the absence of pericardial effusion. Therapy at discharge included colchicine and ibuprofen. At the 2-month follow-up, he was asymptomatic, with a normal value of white blood cell and C-reactive protein and without pericardial effusion. In our case report, the foreign body penetrated the right cavities of the heart, embolizing through the venous bed.

Pericarditis resulted from the inflammation of the epicardium, due to the movement of the heart against the foreign body, which caused pericardial bleeding and local immune response; if untreated, this process may evolve in constrictive pericarditis [8].

The repeated use of intravenous drugs in numerous sites increases the likelihood of finding broken needle fragments. Given the location of the foreign body and the symptomatic presentation of the patient, we performed surgery to remove the foreign body [9].

An alternative therapeutic option for removal of foreign bodies from the heart is the percutaneous approach, with the use of a guidewire through the femoral vein and a magnet at its distal end. This is applicable only for small, intracavitary foreign bodies [10].

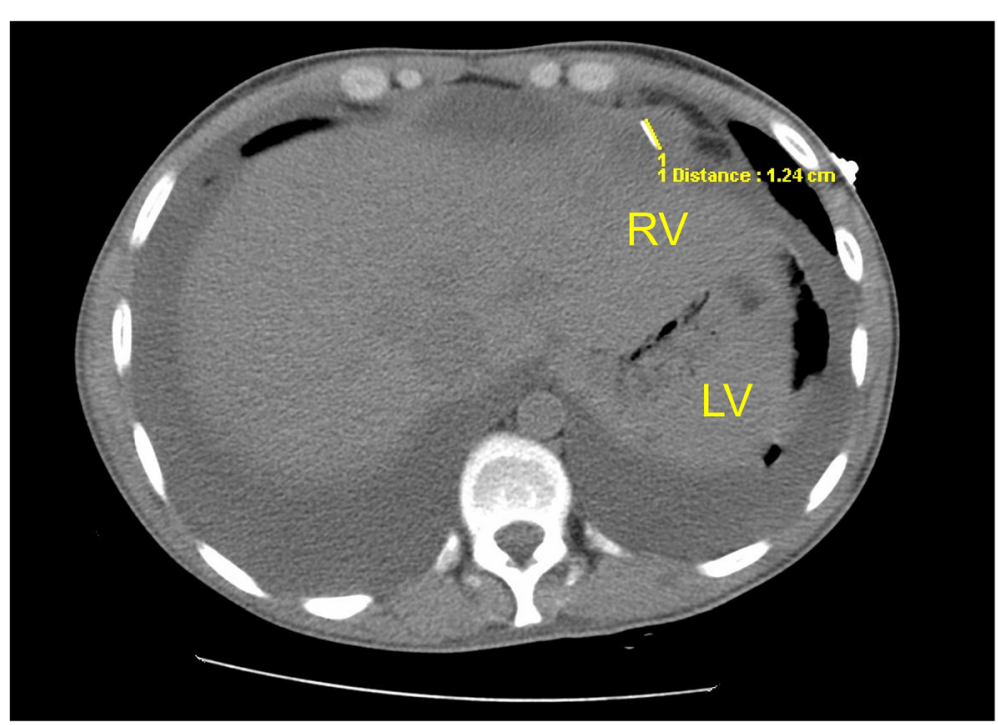

Fig. 1 Thoracic CT without contrast showing the needle beside the pericardium. RV, right ventricle; LV, left ventricle 


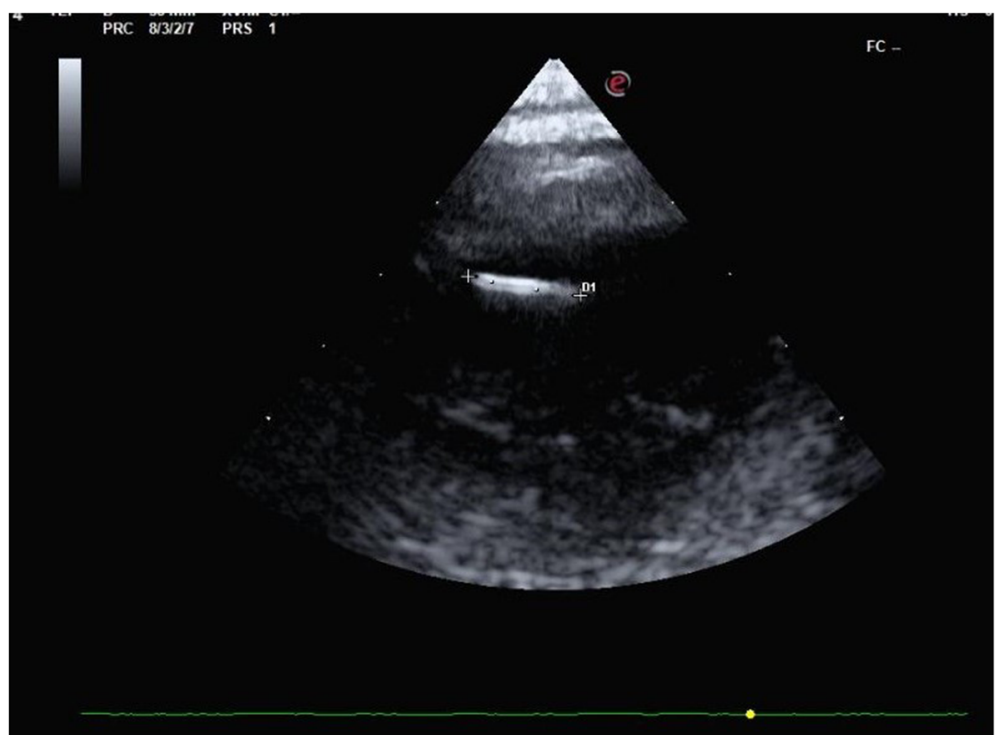

Fig. 2 Echographic image of the needle and the pericardial effusion

The management of foreign bodies in the heart should be individualized: (1) symptomatic foreign bodies should be removed, no matter their location; (2) asymptomatic foreign bodies diagnosed immediately after the injury with a high risk of infection, embolization, or erosions should be removed; (3) asymptomatic foreign bodies without associated risk factors or diagnosed late after the injury may be treated conservatively, particularly if they are completely embedded within the myocardium or the pericardium [5].

To our knowledge, only a few cases of needle embolization in pulmonary vasculature or inside the right heart are reported in the literature, most of them in drug abusers or after iatrogenic accidents [9-15].

Moreover, the literature describes different kinds of foreign bodies reaching the heart from peripheral sites, such as oral ingestion of safety pins causing cardiac injury or pericardial effusion, after migration through the lower oesophagus wall [16-18].

Other causes of foreign body embolization in the right heart and in the pulmonary artery are iatrogenic complications, such as embolization of inferior vena cava filter fragments $[19,20]$, or needle-like cement after percutaneous vertebroplasty [21], or embolization of subdermal contraceptive implants [22], all causing cardiac or pulmonary injury.

\section{Conclusions}

In drug abuse patients, we must consider the possibility of needle embolization. The medical history of these patients is sometimes difficult to acquire. In a drug abuse patient with recurrent pericardial disease, the hypothesis of a foreign body embolization, as in this case, should be part of the differential diagnosis.

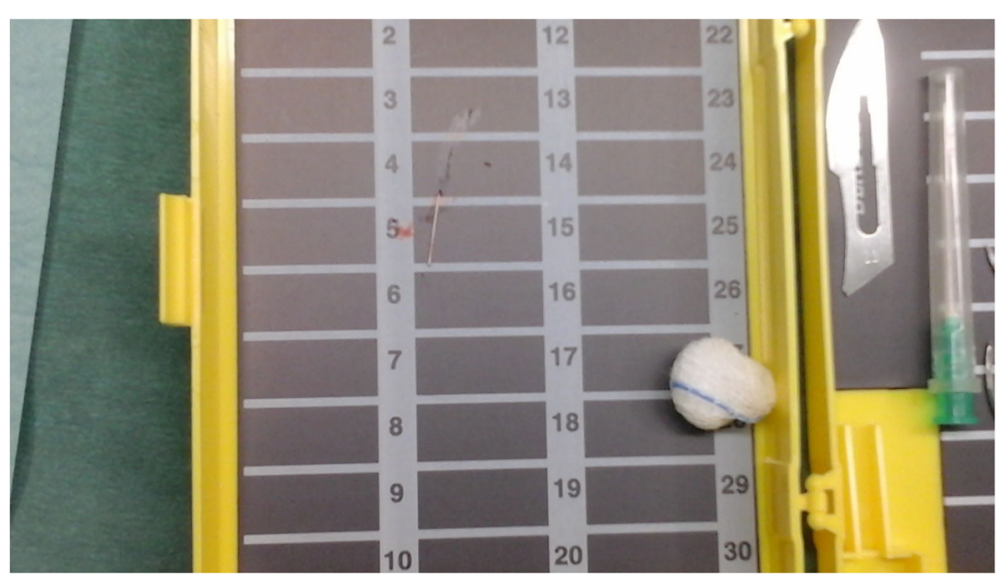

Fig. 3 The needle after surgical extraction 


\section{Abbreviations}

HIV: Human immunodeficiency virus; HBV: Hepatitis B virus; HCV: Hepatitis C virus

\section{Acknowledgements}

Not applicable

\section{Authors' contributions}

VS made the diagnosis and followed the patient. VS and TM wrote the paper. CM revised the manuscript. PLS performed the surgical intervention. All authors read and approved the final manuscript.

\section{Funding}

None to declare

\section{Availability of data and materials}

Not applicable.

Ethics approval and consent to participate

Not applicable.

\section{Consent for publication}

Written informed consent was obtained from the patient.

\section{Competing interests}

The authors declare that they have no competing interests.

\section{Author details}

'Division of Cardiovascular and Perioperative Medicine,

Cardiothoracovascular Department, Azienda Ospedaliero-Universitaria Careggi and University of Florence, Largo Brambilla 3, 50133 Florence, Italy. ${ }^{2}$ Division of General Cardiology, Cardiothoracovascular Department, Azienda Ospedaliero-Universitaria Careggi and University of Florence, Florence, Italy. ${ }^{3}$ Division of Cardiac Surgery, Cardiothoracovascular Department, Azienda Ospedaliero-Universitaria Careggi and University of Florence, Florence, Italy.

Received: 9 October 2020 Accepted: 16 November 2020

Published online: 25 November 2020

\section{References}

1. Kim YJ, Kim JY, Choi BW, Nam JE, Kim TH, Choe KO (2006) Right ventricular acupuncture needle embolism detected on coronary computed tomography angiography. Circulation. 114:e623-e626

2. Wojda TR, Dingley SD, Wolfe S, Terzian WTH, Thomas PG, Vazquez D, Sweeney J, Stawicki SP (2017) Foreign intravascular object embolization and migration: bullets, catheters, wires, stents, filters, and more. https://doi.org/ $10.5772 / 68039$

3. Gandhi SK, Marts BC, Mistry BM, Brown JW, Durham RM, Mazuski JE (1996) Selective management of embolized intracardiac missiles. Ann Thorac Surg 62:290-292

4. Shannon JJ, Vo NM, Stanton PE Jr, Dimler M (1987) Peripheral arterial missile embolization: a case report and 22-year literature review. J Vasc Surg 5:773778

5. Actis Dato GM, Arslanian A, Di Marzio P, Filosso PL, Ruffini E (2003) Post traumatic and iatrogenic foreign bodies in the heart: report of fourteen cases and review of the literature. J Thorac Cardiovasc Surg 126:408-414

6. Roberts WC (2005) Pericardial heart disease: its morphologic features and its causes. Proc (Baylor Univ Med Cent) 18(1):38-55

7. Khandaker $\mathrm{MH}$, Espinosa RE, Nishimura RA, Sinak $\sqcup$, Hayes SN, Melduni RM, Oh JK (2010) Pericardial disease: diagnosis and management. Mayo Clin Proc 85(6):572-593

8. LeMaire SA, Wall MJ Jr, Mattox KL (1998) Needle embolus causing cardiac puncture and chronic constrictive pericarditis. Ann Thorac Surg 65(6):17861787

9. Norfolk GA, Gray SF (2003) Intravenous drug users and broken needles-a hidden risk? Addiction 98:1163-1166

10. Bompotis G, Karkanis G, Chatziavramidis A (2016) Percutaneous removal of a tiny needle fracture from the right ventricle of the heart in a drug abuser. Vasc Endovasc Surg 50:575-578

11. Monroe EJ, Tailor TD, McNeeley MF, Lehnert BE (2012) Needle embolism in intravenous drug abuse. Radiology Case Reports 7:714
12. Yen AF, Homer CM, Mohapatra A, Langnas E, Gomez A, Hendrickson CM (2019) Embolic hypodermic needle causing traumatic cardiac tamponade: a case report. Crit Care Explor 1(8):e0038

13. Levy M, Hahn B, Aycock R (2019) Needle embolization: suspecting needle migration in intravenous drug abusers. J Emerg Med S0736-4679(19):30819_ 30814

14. Dell'Amore A, Ammari C, Campisi A, D'Andrea R (2016) Peripheral venous catheter fracture with embolism into the pulmonary artery. J Thorac Dis 8: E1581-E1584

15. Danek BA, Kuchynka P, Palecek T, Cerny V, Hlavacek K, Lambert L, Nemecek E, Podzimkova J, Linhart A (2016) Needle fragment embolism into the right ventricle: a rare cause of chest pain case report and literature review. Wien Klin Wochenschr 128(5-6):215-220

16. Sugunan S, Ajith Krishnan AS, Devakumar VK, Arif AK (2018) Safety-pin induced hemopericardium and cardiac tamponade in an infant. Indian Pediatr 55(6):521-522

17. Kalayci AG, Baysal K, Uysal S et al (2002) Hemopericardium caused by ingested safety pin. Endoscopy. 34:93

18. Choudhary S, Pujar Venkateshacharya S, Reddy C (2016) Sewing needle: a rare cause of intra-cardiac foreign body in a 3-year-old child. Cardiol Young 26:1425-1427

19. Shennib H, Bowles B, Hickle K (2014) Migration of a fractured inferior vena cava filter strut to the right ventricle of the heart: a case report. J Cardiothorac Surg 9:183

20. Kalavakunta JK, Thomas CS, Gupta V (2009) A needle through the heart: rare complication of inferior vena caval filters. J Invasive Cardiol 21:E221-E223

21. Kong M, Xu X, Shen J, Liu Q, Wang G (2019) Clinical characteristics and management of cardiac and/or pulmonary cement embolus after percutaneous vertebroplasty: a single center experience. Ann Transl Med 7(16):372

22. Hindy JR, Souaid T, Larus CT, Glanville J, Aboujaoude R (2020) Nexplanon migration into a subsegmental branch of the pulmonary artery: a case report and review of the literature. Medicine (Baltimore) 99(4):e18881

\section{Publisher's Note}

Springer Nature remains neutral with regard to jurisdictional claims in published maps and institutional affiliations.

\section{Submit your manuscript to a SpringerOpen ${ }^{\circ}$ journal and benefit from:}

- Convenient online submission

- Rigorous peer review

- Open access: articles freely available online

- High visibility within the field

- Retaining the copyright to your article

Submit your next manuscript at $\boldsymbol{\nabla}$ springeropen.com 